\title{
Postpartum contraception: determinants of intention and methods of use among an obstetric cohort in a tertiary hospital in Jos, North Central Nigeria
}

\author{
Otobo I. Ujah ${ }^{1 *}$, Amaka N. Ocheke ${ }^{1}$, Josiah T. Mutihir'1, \\ Joseph A. Okopi ${ }^{2}$, Innocent A. O. Ujah ${ }^{1}$
}

\begin{abstract}
${ }^{1}$ Department of Obstetrics and Gynecology, Jos University Teaching Hospital, Jos, Nigeria
${ }^{2}$ Department of Microbiology, University of Jos, Plateau, Nigeria
\end{abstract}

Received: 26 September 2017

Accepted: 31 October 2017

\author{
*Correspondence: \\ Dr. Otobo I. Ujah, \\ E-mail: otoboujah@yahoo.com
}

Copyright: () the author(s), publisher and licensee Medip Academy. This is an open-access article distributed under the terms of the Creative Commons Attribution Non-Commercial License, which permits unrestricted non-commercial use, distribution, and reproduction in any medium, provided the original work is properly cited.

\begin{abstract}
Background: Postpartum contraception reduces the risk of unintended and rapid repeat pregnancies. A comprehensive postpartum family planning (PPFP) service can enable women make adequate and informed choices on a preferred contraceptive method, initiating a method as well as encouraging them to use that method for a period depending on their reproductive intentions.

Methods: This study aimed to determine women's intention regarding uptake of postpartum family planning, the preferred methods and the factors associated with uptake. We conducted a cross-sectional study among women attending antenatal and postnatal clinics at the Jos University Teaching Hospital, Jos, Nigeria using structured questionnaires. Data was analyzed using descriptive statistics and chi square test of comparison.

Results: Four hundred and five women participated in the study. The mean age of the respondents was $28.4+5.3$ years. The previous contraceptive usage was 39.8\%. A total of $262(64 \%)$ women intend to use a method of postpartum contraception. The most preferred intended postpartum contraceptive was subdermal implant (19.2\%) followed by injectables $(18.4 \%)$ and intrauterine contraceptive device $(14.7 \%)$. Reasons cited for nonuse of postpartum contraception include spousal refusal, effect on fertility, desire for further child bearing, religious beliefs. Conclusions: Counselling on postpartum contraception during the antenatal and postnatal period can help women make informed choices among the wide range of available contraception.
\end{abstract}

Keywords: Contraception, Condoms, Family planning, Implants, Injectables, Long acting reversible contraceptives, Postpartum

\section{INTRODUCTION}

Following the transition from the Millennium Development Goals (MDGs) to the recently agreed Sustainable Development Goals (SDGs) and other related post 2015 agenda, expanding access and coverage to family planning continues to remain a fundamental pillar to improving health and development especially in low resource settings. Family planning enables individuals and couples to plan their desired number of children as well as spacing and timing of their births. ${ }^{1,2}$

However, despite a wide range of contraceptive options available, a significant proportion of women do not have access to adequate information about contraceptive methods. Also, the failure to practice contraception are influenced by several factors - personal, spousal or environmental. 
Some of these have been attributed to the fear of side effects, lack of access to health facility, preference for male child, religious beliefs, cost, desire for more children and husbands refusal. ${ }^{2-4}$ The antenatal and postnatal period can, however, serve as a window of opportunity to address some of these issues, providing adequate information on the available options and access to contraceptive methods as well as demystifying some of the myths and misconceptions which many women have regarding the use and adoption of family planning methods in the postpartum period. ${ }^{4,5}$ Contraception counselling during the antenatal and postpartum period is also important because pregnancy and childbirth may change a woman's preference for contraception. ${ }^{6}$ Nevertheless, the changing priorities for contraception as well as the dissatisfaction with prior methods may make peripartum women more receptive to considering other methods. ${ }^{5}$ Counselling can no doubt be improved if, on the other hand, the physicians are aware of this populations changing needs.

While several studies have examined patient satisfaction with particular contraceptive methods, only few have studied the peripartum women. ${ }^{5}$ Postpartum family planning is defined as the prevention of unintended pregnancy and closely spaced pregnancies through the first 12 months following childbirth. ${ }^{7,8}$ A comprehensive postpartum family planning (PPFP) service should therefore enable women make adequate and informed choices on a preferred contraceptive method, starting that method while encouraging them to use that method for 2 years or more depending on their reproductive intentions. ${ }^{9}$ Hence understanding factors that influence postpartum contraceptive choice, initiation and adherence could inform strategies to reduce unplanned and rapid repeat pregnancy as these have increased risk of complications such as preterm deliveries and low birth weight. ${ }^{10}$ The objectives of this study were to determine the proportion of women who intend to adopt postpartum contraception, women's choices on a method of postpartum contraception and factors associated with use and non-use of a postpartum contraception.

\section{METHODS}

We conducted a cross-sectional descriptive study among pregnant and postpartum women who attended antenatal and postnatal clinics at the Jos University Teaching Hospital. These clinics run simultaneously from Mondays through Thursdays, beginning 8 am daily. The study was carried out from 1 August 2015 to 30 October 2015. The questionnaire was tested on women who were attending the antenatal and postnatal clinics after which modifications were made to the questionnaires to eliminate areas of ambiguity. Thereafter, all married women who were either pregnant or within six weeks postpartum (irrespective of pregnancy outcome) and who consented to partake in the study were administered already tested structured questionnaires. The questionnaire consisted of 2 parts: the first part collected demographic characteristics of eligible women while the second part assessed women's knowledge about contraceptives, previous contraceptive usage, if index or recent pregnancy was planned or not, intention to use contraceptives postpartum and intended duration of birth spacing. The minimum sample size required for this study was calculated using the Fisher's formula $\left(\mathrm{N}=\mathrm{Z}^{2} \mathrm{pq} / \mathrm{d}^{2}\right)$. Using a prevalence of $89.1 \%(\mathrm{p}=0.89)$, who intended to use postpartum family planning in a study by Idowu et al, the sample size was calculated to be 150 with 95\% confidence level and 5\% precision of estimate $(\mathrm{d}=0.05) .{ }^{11}$ This sample size was however adjusted to compensate for a non-response rate of $20 \%$ and the final minimum sample size was 180. Six assistants were trained on adequate data administration. Data collected were first manually entered into an excel spreadsheet and then exported and analyzed using STATA 12.1 (Stata Corp. LP, College Station, TX, USA). A Fisher's exact test was used to determine statistical significance between variables.

\section{RESULTS}

Table 1: Sociodemographic characteristics of respondents.

\begin{tabular}{|c|c|c|}
\hline & Antepartum & Postpartum \\
\hline Characteristic & n $(\%)$ & n $(\%)$ \\
\hline \multicolumn{3}{|l|}{ Age group } \\
\hline$\leq 20$ & $35(10.9)$ & $1(1.2)$ \\
\hline $21-25$ & $65(20.2)$ & $23(27.7)$ \\
\hline $26-30$ & $120(37.3)$ & $24(28.9)$ \\
\hline $31-35$ & $83(25.8)$ & $22(26.5)$ \\
\hline $36-40$ & $17(5.3)$ & $11(13.3)$ \\
\hline$>40$ & $2(0.6)$ & $2(2.4)$ \\
\hline \multicolumn{3}{|l|}{ Education } \\
\hline None & $14(4.3)$ & $2(2.4)$ \\
\hline Primary & $19(5.9)$ & $8(9.6)$ \\
\hline Secondary & $120(37.3)$ & $31(37.4)$ \\
\hline Post-secondary & $169(52.5)$ & $42(50.6)$ \\
\hline \multicolumn{3}{|l|}{ Employment } \\
\hline Unemployed & $145(45.0)$ & $28(33.7)$ \\
\hline Employed & $177(55)$ & $55(66.3)$ \\
\hline \multicolumn{3}{|c|}{ Duration of marriage } \\
\hline$\leq 1$ & $82(25.5)$ & $24(28.9)$ \\
\hline$\overline{2}-5$ & $116(36.0)$ & $2732.5)$ \\
\hline $6-10$ & $71(22.0)$ & $20(24.1)$ \\
\hline$>10$ & $53(16.5)$ & $12(14.5)$ \\
\hline \multicolumn{3}{|c|}{ Number of living children } \\
\hline 0 & $104(32.3)$ & $0(0)$ \\
\hline 1 & $105(32.6)$ & $29(29)$ \\
\hline $2-4$ & $94(29.2)$ & $46(55.4)$ \\
\hline$\geq 5$ & $19(5.9)$ & $8(9.6)$ \\
\hline \multicolumn{3}{|l|}{$\overline{\text { Religion }}$} \\
\hline Christian & $192(59.6)$ & $62(74.7)$ \\
\hline Muslim & $130(40.4)$ & $21(25.3)$ \\
\hline \multicolumn{3}{|c|}{ Pregnancy intention } \\
\hline Unintended & $83(25.8)$ & $26(31.3)$ \\
\hline Intended & $239(74.2)$ & $57(68.7)$ \\
\hline
\end{tabular}


The total number of respondents interviewed was 405 of which $322(80 \%)$ were pregnant and $83(20 \%)$ were women who had delivered within 6 weeks. As shown in

Table 1 , the mean age of the respondents was $28.4+5.3$ years (range 16-47 years). All participants interviewed were married. The mean duration of marriage was $5.7+5.1$ years $(0-22$ years $)$. Two hundred and fifty-four $(62.7 \%)$ were Christians and 151 (37.3\%) were Muslims.

Majority of the respondents $(52.1 \%)$ were educated beyond secondary level of education. Only $16(4.0 \%)$ had no formal education. Overall, $109(27 \%)$ said the index or most recent pregnancy was unplanned. The previous modern contraceptive usage was $39.8 \%$ while $60.2 \%$ have never used any modern contraceptive method.

Among women who had ever used contraception, the most common contraceptive method used was injectables $(28.7 \%)$ followed by male condoms $(24.2 \%)$, intrauterine contraceptive device (17.8\%), oral contraceptive pills $(17.2 \%)$ and implants $(10 \%)$.

A total of $262(64 \%)$ women intend to use a method of postpartum contraception, $95(23.5 \%)$ did not intend to use any form of contraception while 48 (11.9\%) were undecided as to whether or not they wanted to use any method of contraception.

Table 2: Demographic characteristics and the use of postpartum contraception $(n=262)$.

\begin{tabular}{|c|c|c|c|c|c|}
\hline \multicolumn{6}{|c|}{ Intention to use postpartum contraception } \\
\hline & No & Yes & Undecided & Total & $p$-value \\
\hline Characteristics & n $(\%)$ & n $(\%)$ & n $(\%)$ & n $(\%)$ & \\
\hline \multicolumn{6}{|l|}{ Age group } \\
\hline$<20$ & $19(52.8)$ & $11(30.6)$ & $6(16.7)$ & $36(8.9)$ & 0.00 \\
\hline $21-25$ & $18(20.5)$ & $58(65.9)$ & $12(13.6)$ & $88(21.7)$ & \\
\hline $26-30$ & $34(23.6)$ & $93(64.6)$ & $17(11.8)$ & $144(35.6)$ & \\
\hline $31-35$ & $21(20.0)$ & $75(71.4)$ & $9(8.6)$ & $105(25.9)$ & \\
\hline $36-40$ & $2(7.1)$ & $22(78.6)$ & $4(14.3)$ & $28(6.9)$ & \\
\hline$>40$ & $1(25.0)$ & $3(75.0)$ & $0(0.0)$ & $4(1)$ & \\
\hline Total & $95(23.5)$ & $262(64.7)$ & $48(11.9)$ & $405(100.0)$ & \\
\hline \multicolumn{6}{|l|}{ Education } \\
\hline None & $4(25.0)$ & $12(75.0)$ & $0(0.0)$ & $16(4.0)$ & 0.17 \\
\hline Primary & $8(29.6)$ & $16(58.3)$ & $3(11.1)$ & $27(6.7)$ & \\
\hline Secondary & $44(29.1)$ & $92(60.9)$ & $15(9.9)$ & $151(37.3)$ & \\
\hline Post-secondary & $39(18.5)$ & $142(67.3)$ & $30(14.2)$ & $211(52.1)$ & \\
\hline Total & $95(23.5)$ & $262(64.7)$ & $48(11.9)$ & $405(100.0)$ & \\
\hline \multicolumn{6}{|c|}{ Number of living children } \\
\hline 0 & $29(27.9)$ & $53(51.0)$ & $22(21.2)$ & $104(25.7)$ & 0.00 \\
\hline 1 & $42(31.3)$ & $72(53.7)$ & $20(14.9)$ & $134(33.1)$ & \\
\hline $2-4$ & $20(14.3)$ & $114(81.4)$ & $6(4.3)$ & $140(34.6)$ & \\
\hline$>5$ & $4(14.8)$ & $23(85.2)$ & $0(0.0)$ & $27(6.7)$ & \\
\hline Total & $95(23.5)$ & $262(64.7)$ & $48(11.9)$ & $405(100.0)$ & \\
\hline \multicolumn{6}{|c|}{ Duration of marriage } \\
\hline$<1$ & $25(23.6)$ & $62(58.5)$ & $19(17.9)$ & $106(26.2)$ & 0.00 \\
\hline $2-5$ & $41(28.7)$ & $81(56.6)$ & $21(14.7)$ & $143(35.3)$ & \\
\hline $6-10$ & $20(22.0)$ & $64(70.3)$ & $7(7.7)$ & $91(22.5)$ & \\
\hline$>10$ & $9(13.8)$ & $55(84.6)$ & $1(1.5)$ & $65(16.1)$ & \\
\hline Total & $95(23.5)$ & $262(64.7)$ & $48(11.9)$ & $405(100.0)$ & \\
\hline \multicolumn{6}{|l|}{ Religion } \\
\hline Christian & $51(20.1)$ & $169(66.5)$ & $34(13.4)$ & $254(62.72)$ & 0.08 \\
\hline Muslim & $44(29.1)$ & $93(61.6)$ & $14(9.3)$ & $151(37.3)$ & \\
\hline Total & $95(23.5)$ & $262(64.7)$ & $48(11.9)$ & $405(100.0)$ & \\
\hline \multicolumn{6}{|c|}{ Pregnancy intention } \\
\hline Unintended & $21(19.3)$ & $82(75.2)$ & $6(5.5)$ & $109(26.91)$ & 0.01 \\
\hline Intended & $74(25.0)$ & $180(60.8)$ & $42(14.2)$ & $296(73.1)$ & \\
\hline Total & $95(23.5)$ & $262(64.7)$ & $48(11.9)$ & $405(100)$ & \\
\hline
\end{tabular}


When asked to indicate their preferred choice of contraception in the postpartum period (Table 2), majority $(25.9 \%)$ were undecided. However, $51(19.2 \%)$ preferred to use the subdermal implant, 49 (18.4\%) preferred injectables, $39 \quad(14.7 \%)$ intrauterine contraceptive device, $21(7.9 \%)$ preferred a natural method, $15(5.6 \%), 11(4.14 \%)$ wanted to use the male condoms. Only $10(3.8 \%)$ wanted a permanent method of contraception.

Among women who previously used a method of contraception $(n=161), 55(34.2 \%)$ wanted to continue using the previous method for postpartum contraception. Of the 95 women who did not want to use a method of contraception postpartum $27(28.4 \%)$ said they desired further childbearing, $12(12.6 \%)$ attributed their nonuse to their spousal related factors (refusal, consent, unavailability) (Table 3). Among respondents who gave duration of intended child spacing $(n=314)$, the mean duration of child spacing was 3.2+1.4 years (range 1-10 years). Sixty-four (15\%) women desired no further childbearing and $27(6.7 \%)$ were undecided as to the duration of their intended child spacing.

Table 3: Reasons for not wanting to use contraception $(\mathbf{n}=95)$.

\begin{tabular}{|lll|}
\hline Reasons & Frequency & $\begin{array}{l}\text { Percentage } \\
(\mathbf{n})\end{array}$ \\
\hline Spousal refusal/consent & 12 & 12.6 \\
\hline Don't like it & 5 & 5.3 \\
\hline Fear of effect on fertility & 3 & 3.2 \\
\hline $\begin{array}{l}\text { Desire for further } \\
\text { childbearing }\end{array}$ & 27 & 28.4 \\
\hline Medical reasons & 1 & 1.1 \\
\hline Religious belief & 2 & 2.1 \\
\hline Side effects & 19 & 20.0 \\
\hline No reason & 26 & 27.4 \\
\hline Total & 95 & 100.0 \\
\hline
\end{tabular}

\section{DISCUSSION}

There is indeed a great chance that many couples may initiate sexual activity prior to 6 weeks postpartum and therefore risking the chance of having an unintended or rapid repeat pregnancy.

The risk is especially high if women do not exclusively breastfeed their babies during this period. ${ }^{9}$ Therefore, interaction with women during antenatal care, delivery, postnatal and immunization clinics offer unique opportunities to be counselled and offered their preferred choice of contraception.

This study therefore aims to highlight women's prior knowledge and use of contraception as well as assessing their intention to embark on a postpartum contraceptive method before their next desired planned pregnancy. The study participants were all married. The previous contraceptive uptake from this study was $39.8 \%$. This is similar to the rate observed in a study by Okunowo et al., which showed a previous contraceptive uptake prevalence rate of $35.5 \%$. However much higher prevalence rates have been reported in other studies. . $^{1,-6}$

The low utilization of contraception appears to be influenced by other factors. The plausible reasons for this as reflected in this study were due to the desire for further child bearing, religious beliefs, husband's influence/refusal, fear of effect on future fertility and possible complications or side effects from the contraceptives. Sixty-four percent of respondents intended to use a method of contraception postpartum. This is $10 \%$ higher than the rate observed in the study by Okunowo et al. ${ }^{4}$

Chouudhary et al reported $90.5 \%$ of respondents intending to use postpartum contraception after they were counselled. ${ }^{1}$ Higher proportions of postpartum contraceptive intentions were also reported in other studies. ${ }^{3,11,12}$ We also found that among women who intended to use a contraceptive postpartum, the rates were higher among women who were aged 31-35 years (71.4\%), had post-secondary education $(67.3 \%)$, had 2-4 children alive, married for 2-5 years $(56.6 \%)$, were Christians $(66.5 \%)$ and whose pregnancies were intended $(60.8 \%)$. This may therefore suggest that women's age, level of education, parity, religion and duration of marriage play an integral role in uptake and utilization of postpartum contraception. This is also reflected in the study by Rutaremwa et al, which showed that utilization of modern postpartum family planning was significantly associated with women's education level, wealth status, religion, age of the woman, number of surviving children, exposure to the media and utilization of reproductive health services. ${ }^{8}$

The most preferred contraceptive methods from our study were the implants (19.2\%) and injectables (18.4\%). Rahmanpour et al found that the most preferred contraceptive used after delivery were the minipill (29.3\%) and the intrauterine contraceptive device (25\%) while in the study by Chaovisitsaree et al. ${ }^{12,13}$ Depot medroxy progesterone acetate $(38.4 \%)$ and the progestinonly pills $(26.0 \%)$ were the preferred postpartum contraceptive methods. In a similar Nigerian study, the condom $(38.3 \%)$ and the intrauterine contraceptive device $(11.5 \%)$ were the most preferred. ${ }^{4}$

We observe from the above figures, that in some other parts of the world, the oral contraceptive pills tend to be favoured more compared to the implants and the intrauterine contraceptive device. It is possible that these methods are easily affordable, readily accessible and do not necessarily require a skilled provider. These findings show also that among women who had previously used a contraceptive method $(n=161), 55(34.2 \%)$ were satisfied with the previous method and wanted to continue with the same method in the postpartum period. 
Present study therefore highlights the challenges in adequately ensuring and meeting the postpartum contraceptive needs of women. We observe that majority of the women are undecided as to the method of postpartum contraception they would opt for. This could either be due to limited knowledge of the available contraceptive methods or the influence of language barrier given that large numbers with diverse ethnicity and levels of education seek care at our facility.

The need to engage partners and religious leaders in clarifying misguided information and misconceptions regarding contraceptive use may be a huge step in the right direction in improving women's uptake and utilization of contraceptives in the postpartum period as this clearly has shown benefit in reducing maternal and neonatal morbidities and mortalities. ${ }^{3-6,9,11}$

The effectiveness of prenatal and postnatal counselling on postpartum contraceptive uptake can be improved through development and adoption and adapting institutionalized protocols as well as staff training. It has also been found that despite women indicating and stating their preference for a postpartum contraceptive method, these women were not using the method they had chosen and hence a reflection of wide gaps in prenatal contraceptive counselling. ${ }^{5}$ It is also suggested that while providers are entitled to provding women with the full range of widely available contraceptive methods, following a tiered approach should be imbibed. In doing so, women are provided with information on the most effective methods before providing information on the less effective methods. ${ }^{6}$

The recent best practice in postpartum family planning by the Royal College of Obstetricians and Gynaecologists has provided information on the various contraceptive methods and their effectiveness. ${ }^{9}$ It is therefore important for women to have a method of contraception they can start before the chances of pregnancy returns soon after delivery.

This study has limitations. Of the respondents sampled, majority $(79.5 \%)$ were pregnant and only $20.5 \%$ were postpartum. This could be as a result of the fact that many women do not seek postnatal care after childbirth. Researching into factors associated with this would be beneficial. Furthermore, since it was a questionnaire based survey, it may be difficult to measure or assess the accuracy of women's responses to the questions.

We would therefore recommend that qualitative research in this area are designed to further understand more clearly, factors that may serve as road blocks towards women utilizing postpartum contraceptive and adequate steps to overcome them by creating greater individual based awareness and formulating policies which will be major steps in achieving the Sustainable Development Goals (SDGs).

\section{ACKNOWLEDGMENTS}

Authors would like to thank the management of the Jos University Teaching Hospital for allowing us carry out this study in her facility and also the participants who consented to participate in this study.

Funding: No funding sources

Conflict of interest: None declared

Ethical approval: The study was approved by the Institutional Ethics Committee

\section{REFERENCES}

1. Choudhary D, Pal R, Goel N. Awareness and practice patterns of family planning methods. Biomed J. 2015;34:356-8.

2. Di Giacomo P, Sbarlati A, Bagnasco A, Sasso L. Woman's contraceptive needs and preferences in the postpartum period: an Italian study. J Clin Nurs. 2013;22:3406-17.

3. Eliason S, Baiden F, Quansah-Asare G, GrahamHayfron Y, Bonsu D, Phillips J et al. Factors influencing the intention of women in rural Ghana to adopt postpartum family planning. Reprod Health. 2013;10:1-8.

4. Adegbola O, Okunowo A. Intended postpartum contraceptive use among pregnant and puerperal women at a university teaching hospital. Arch Gynecol Obstet. 2009;280:987-92.

5. Cwiak C, Gellasch T, Zieman M. Peripartum contraceptive attitudes and practices. Contraception. 2004;70:383-6.

6. Zapata LB, Murtaza S, Whiteman MK, Jamieson DJ, Robbins CL, Marchbanks PA, et al. Contraceptive counseling and postpartum contraceptive use. Am J Obstet Gynecol. 2015;212:171.e1-8.

7. World Health Organization. Programming strategies for postpartum family planning. Geneva: WHO; 2013. Available at http://www.who.int/reproductivehealth/publications/f amily_planning/ppfp_st rategis/en/

8. Rutaremwa G, Kabagenyi A, Wandera SO, Jhamba T, Akiror E, Nviiri HL. Predictors of modern contraceptive use during the postpartum period among women in Uganda: a population-based cross sectional study. BMC Public Health. 2015;15:262.

9. Royal College of Obstetricians \& Gynaecologists. Postpartum family planning (Best Practice Paper No.1). United Kingdom: RCOG; 2015 Available at www.rcog.org.uk/en/guidelines-researchservices/guidelines/bpp1/

10. Singh RH, Rogers RG, Leeman L, Borders N, Highfill J, Espey E. Postpartum contraceptive choices among ethnically diverse women in New Mexico. Contraception. 2014;89:512-5.

11. Idowu A, Deji SA, Ogunlaja O, Olajide SO. Determinants of intention to use post partum family planning among women attending immunization 
clinic of a tertiary hospital in Nigeria. Am J Public Heal Res. 2015;3:122-7.

12. Rahmanpour H, Mousavinasab SN, Hosseini SN, Shoghli A. Preferred postpartum contraception methods and their practice among married women in Zanjan, Iran. J Pak Med Assoc. 2010;60:714-8.

13. Chaovisitsaree S, Noi-um S, Kietpeerakool C. Review of postpartum contraceptive practices at chiang mai university hospital: Implications for improving quality of service. Med Princ Pract. 2012;21:145-9.

Cite this article as: Ujah OI, Ocheke AN, Mutihir JT, Okopi JA, Ujah IAO. Postpartum contraception: determinants of intention and methods of use among an obstetric cohort in a tertiary hospital in Jos, North Central Nigeria. Int J Reprod Contracept Obstet Gynecol 2017;6:5213-8. 